\title{
Experimental Studies of The Impermeability of Basalt Fiber High Performance Concrete
}

\author{
Wei Fan, Feng Chen \\ Fujian Province Collaborative Innovation Center for Environmentally Friendly and Energy Saving \\ High Performance Concrete, Fujian Jiangxia University, Fuzhou, Fujian, 350108, China
}

\section{Fw408@163.com,cfxh@fjjxu.edu.cn}

Keywords: basalt fiber; high performance concrete; permeability test system; impermeability Abstract. The Autoclam tester was used to measure the air permeability, hydroscopicity and water permeability of the high performance concrete mixed with basalt fiber. The effect of the content of fly ash and basalt fiber on the impermeability of high performance concrete was analyzed. The results showed that the addition of $1.2 \mathrm{~kg} / \mathrm{m}^{3}$ basalt fiber works most effectively in strengthening the impermeability of concrete, based on the three assessment indexes of Autoclam permeability test system.

\section{Introduction}

Concrete engineering projects like the subsurface structures exposed to abundant underground water and coastal maritime structures are easy to come under permeation by air and underground water, thus bringing a huge challenge to durability of these structures[1,2]. Serving as the media that most frequently contact with concrete, air and water molecules will permeate into concrete through air voids. Besides, water molecules will resolve other harmful ions. Chloride ion, the most harmful ion, will rust reinforcing steel bars where there is air. It degrades concrete performance, severely threatens concrete structure safety, shortens its service life and incurs huge economic losses. Thus, great importance should be attached to the impermeability of concrete. In recent years, many scholars have studied the impermeability of fiber concrete[3-6]. However, the impermeability of high performance concrete mixed with basalt fiber of underground structures was seldom reported. By using Autoclam permeability tester, we tested the air permeability, hydroscopicity and water permeability of the concrete mixed with varying amounts of basalt fiber, in an effort to ascertain the effect of the content of basalt fiber on the impermeability of high performance concrete.

\section{Experimental study}

\section{Mixture proportioning}

In accordance with relevant standards, existing research achievements and the trial concrete mixture, the mixture proportioning for the high performance concrete involved in our study was determined, as shown in Table 1. The test pieces in the experiment were standard concrete samples of $150 \times 150 \times 150 \mathrm{~mm}$.

Table 1. List of concrete mixture proportioning in the experiment

\begin{tabular}{llllll}
\hline Experiment No. & 1 & 2 & 3 & 4 & 5 \\
\hline Cement $/ \mathrm{kg} / \mathrm{m}^{3}$ & 350 & 350 & 350 & 350 & 350 \\
Fly ash $/ \mathrm{kg} / \mathrm{m}^{3}$ & 150 & 150 & 150 & 150 & 150 \\
Fine aggregate $/ \mathrm{kg} / \mathrm{m}^{3}$ & 649 & 649 & 649 & 649 & 649 \\
Coarse aggregate $/ \mathrm{kg} / \mathrm{m}^{3}$ & 1058 & 1058 & 1058 & 1058 & 1058 \\
Water $/ \mathrm{kg} / \mathrm{m}^{3}$ & 160 & 160 & 160 & 160 & 160 \\
Fiber $/ \mathrm{kg} / \mathrm{m}^{3}$ & 0 & 1 & 1.2 & 1.4 & 1.6 \\
Water reducer $/ \mathrm{kg} / \mathrm{m}^{3}$ & 5.5 & 5.5 & 5.5 & 5.5 & 5.5 \\
\hline
\end{tabular}




\section{Testing apparatus and operation}

The Autoclam water and air permeability testing system, developed by Queen's University (Belfast, Northern Ireland, UK), was used as the testing apparatus in our experiment. The apparatus is composed of main engine and electronic control device. It can be used to test air permeability, hydroscopicity and water permeability of concrete and other porous materials. With the apparatus, we can find out the air-pressure attenuation rate during the air permeability test and the hydroscopicity and water permeability of concrete under constant pressure.

As required by the apparatus, if the air permeability, hydroscopicity or water permeability is to be tested at the same position, air permeability should be tested first, followed by tests on hydroscopicity or water permeability. What's more, hydroscopicity test and water permeability test should be performed in different positions. Following the standard curing (temperature: $20 \pm 2{ }^{\circ} \mathrm{C}$, relative humidity: above $95 \%$ ) for 28 days, test pieces were transferred to the room with constant temperature and humidity (temperature: $40 \pm 2{ }^{\circ} \mathrm{C}$, relative humidity: $12 \pm 2 \%$ ) and kept for 2 weeks to eliminate the effect of humidity on the experiment. The test pieces were fastened to the Autoclam tester with fixture, as shown in Figure 1. Air permeability was tested first. One hour later, hydroscopicity was tested. Water permeability was then tested at a different position. The operation interface of the tester is shown in Figure 2.

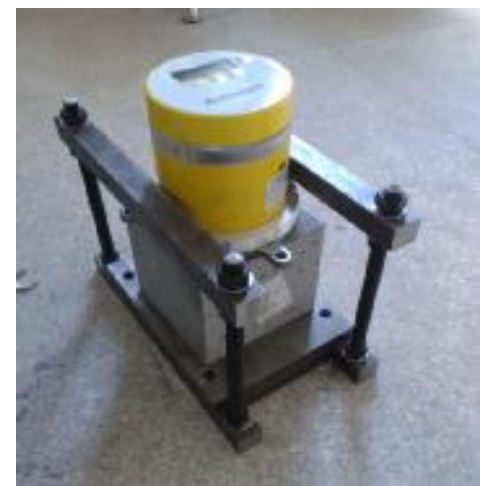

Figure 1 Test apparatus

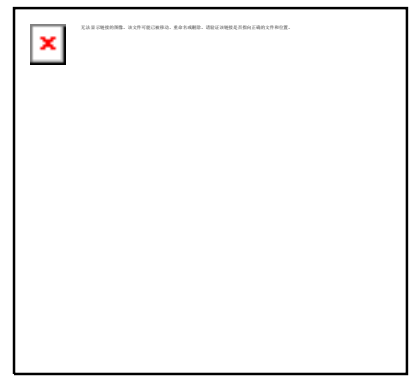

Figure 2 Operation interface of Autoclam tester

\section{Experiment evaluation indexes}

The concrete quality was graded in accordance with the coefficients of air permeability, hydroscopicity and water permeability determined by the Autoclam testing system. See evaluation indexes in Table 2.

Table 2. Quality grade based on the test coefficients

\begin{tabular}{cccc}
\hline $\begin{array}{c}\text { Quality } \\
\text { grade }\end{array}$ & $\begin{array}{c}\text { Autoclam air permeability } \\
\text { coefficient } \\
\mathrm{L}_{\mathrm{n}} / \mathrm{min}\end{array}$ & $\begin{array}{c}\text { Autoclam } \\
\text { hydroscopicity } \\
\text { coefficient } \\
/ \mathrm{m}^{3} / \mathrm{min}^{-2}\end{array}$ & $\begin{array}{c}\text { Autoclam water } \\
\text { permeability coefficient } \\
/ \mathrm{m}^{3} / \mathrm{min}^{-2}\end{array}$ \\
\hline Excellent & $\leqslant 0.1$ & $\leqslant 1.3$ & $\leqslant 3.7$ \\
Good & $0.1 \sim 0.5$ & $1.3 \sim 2.6$ & $3.7 \sim 9.4$ \\
Poor & $0.5 \sim 0.9$ & $2.6 \sim 3.4$ & $9.4 \sim 13.8$ \\
Very poor & $>0.9$ & $>3.4$ & $>13.8$ \\
\hline
\end{tabular}

\section{Experimental results}

The Autoclam testing system is able to automatically compute the coefficients of air permeability, hydroscopicity and water permeability. In the experiment, each index was the average value of three test pieces from the same group. The experimental results are shown in Table 3. 
Table 3. Testing results of water and air permeability

\begin{tabular}{cccc}
\hline $\begin{array}{c}\text { Experiment } \\
\text { No. }\end{array}$ & $\begin{array}{c}\text { Autoclam air } \\
\text { permeability coefficient } \\
\mathrm{L}_{\mathrm{n}} / \mathrm{min}\end{array}$ & $\begin{array}{c}\text { Autoclam } \\
\text { hydroscopicity } \\
\text { coefficient } \\
/ \mathrm{m}^{3} / \mathrm{min}^{-2}\end{array}$ & $\begin{array}{c}\text { Autoclam water } \\
\text { permeability coefficient } \\
/ \mathrm{m}^{3} / \mathrm{min}^{-2}\end{array}$ \\
\hline 1 & 0.05874 & 0.28320 & 1.01457 \\
2 & 0.03754 & 0.14908 & 0.59713 \\
3 & 0.03686 & 0.12587 & 0.88380 \\
4 & 0.03544 & 0.10907 & 1.74458 \\
5 & 0.04806 & 0.34009 & 1.77737 \\
\hline
\end{tabular}

The tendency chart, in which the coefficients of air permeability, hydroscopicity and water permeability vary with the content of basalt fiber, can be drawn based on Table 3. See Figure 3-5.

- BFHPC

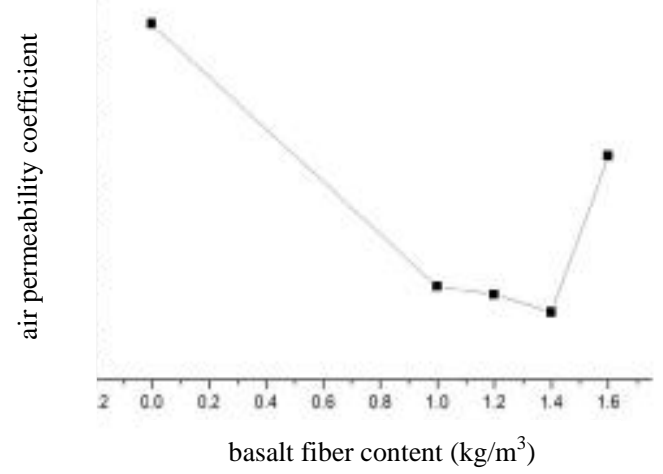

Figure 3 The effect of basalt fiber content on air permeability coefficient

- $B F H P C$

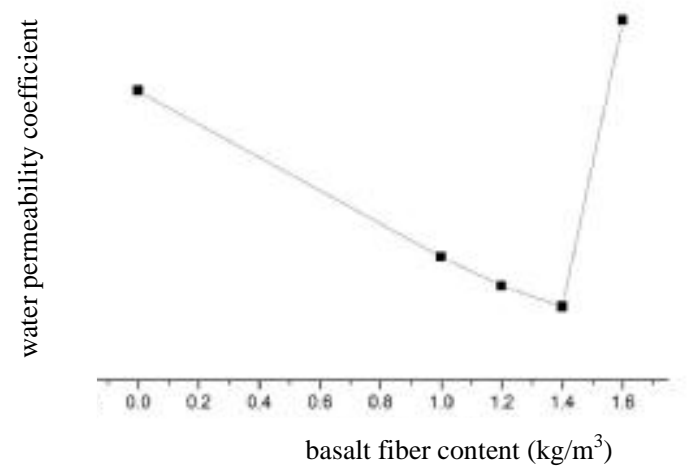

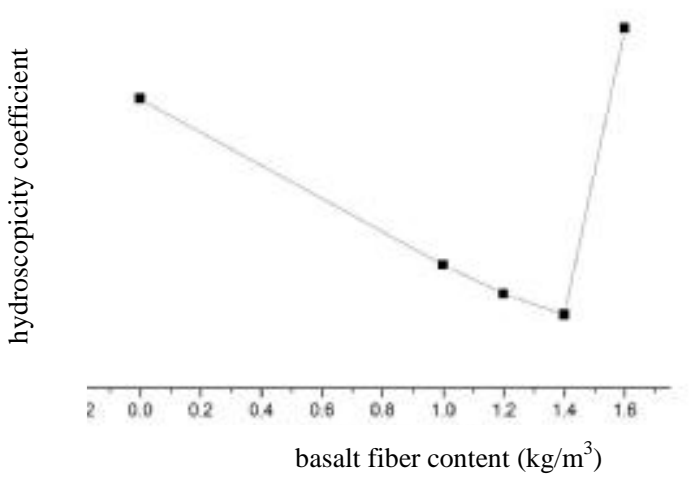

Figure 4 The effect of basalt fiber content on hydroscopicity coefficient

Figure 5 The effect of basalt fiber content on water permeability coefficient

According to the evaluation indexes in Table 2, the smaller the Autoclam coefficient of air permeability, hydroscopicity and water permeability become, the better the concrete impermeability performs and the higher grade the concrete quality ranks. The test pieces in our experiment have a higher quality grade, as evidenced by the experimental results of air permeability, hydroscopicity and 
water permeability and relevant evaluation indexes. It suggests that the concrete tested has an excellent impermeability.

The data in Table 3 and Fig. 3-5 show that the addition of basalt fiber to high performance concrete lowered the coefficients of air permeability and hydroscopicity to varying degrees, but the results of water permeability coefficient were mixed. The air permeability coefficient when the basalt fiber content was $1.0 \mathrm{~kg} / \mathrm{m}^{3}, 1.2 \mathrm{~kg} / \mathrm{m}^{3}, 1.4 \mathrm{~kg} / \mathrm{m}^{3}$ and $1.6 \mathrm{~kg} / \mathrm{m}^{3}$ fell by $36.09 \%, 37.24 \%, 39.67 \%$ and $18.18 \%$ respectively, compared with Group 4 in which the normal concrete without basalt fiber was applied. In other words, the air permeability coefficient fell first and then rose, and it fell to the lowest when the basalt fiber content was $1.4 \mathrm{~kg} / \mathrm{m}^{3}$. The hydroscopicity coefficient dropped by $47.36 \%$, $55.55 \%$ and $61.49 \%$ until it rose suddenly to a value even larger than that of Group 4 when the basalt fiber content was $1.6 \mathrm{~kg} / \mathrm{m}^{3}$. Due to the addition of basalt fiber, water permeability coefficient fell first and then rose sharply by $71.95 \%$ and $75.18 \%$, compared with that of Group 4 . Based on the coefficients of air permeability and hydroscopicity, $1.4 \mathrm{~kg} / \mathrm{m}^{3}$ is the optimal content of basalt fiber. At this point, however, the water permeability coefficient was relatively large, even larger than that of normal concrete. Therefore, when all the three evaluation indexes of Autoclam are taken into account, we found that the basalt fiber content of $1.2 \mathrm{~kg} / \mathrm{m}^{3}$ shall be most helpful to concrete impermeability in the present study.

\section{Conclusions}

With the addition of basalt fiber, air permeability coefficient and hydroscopicity coefficient fell to varying degrees, but the results of water permeability coefficient were mixed. As the fiber content increased, the coefficients of air permeability, hydroscopicity and water permeability all grew greatly after an initial fall. In particular, the hydroscopicity coefficient rose suddenly after a continuous decline. Considering the three evaluation indexes of Autoclam, $1.2 \mathrm{~kg} / \mathrm{m}^{3}$ is determined as the optimal content of basalt fiber for strengthening concrete impermeability.

The Autoclam permeability testing system works effectively in testing the air and water permeability of concrete as well as its hydroscopicity. Thus, it is applicable to qualitative evaluation of the durability of high performance concrete in practice.

\section{Acknowledgement}

This work was financially supported by the natural science foundation of Fujian Province (2010J05110) ( 2016J01726), and Project of education department of Fujian Province (JAT160341).

\section{References}

[1] Singh S. P., Singh B. \& Kaushik S. K. 2005. Probability of Fatigue Failure of Steel Fibrous Concrete. Magazine of Concrete Research. 57(2): 65-72.

[2] Jong S. S., Charlwood P. \& Do Y. M. 2005. Characteristics of basalt fiber as a strengthening material for concrete structures. Composites: Part B, 36(6):504-510.

[3] WANG K. J., SHAH S. P.\& PHUAKSUK P. 2001. Plastic shringkage cracking in concrete materials-influence of fly ash and fibers.ACI Materials Journal, 98(6): 28-34.

[4] Parviz S.\& Siavosh R. 2004. Control of Plastic Shrinkage Cracking with Specialty Cellulose Fibers.ACI Materials Journal, (4):429-435.

[5] Bin W., Cao H. L.\& Song S. H. 2010. Environmental resistance and mechanical performance of basalt and glass fibers. Materials Science and Engineering A, 527(19): 4708-4715.

[6] Marco D. L., Andrea P.\& Gaetano M. 2010. Structural upgrade using basalt fibers for concrete confinement. Journal Composites for Construction, 14(5): 541-552. 